\title{
Comparison of energy efficiency between variable refrigerant flow systems and ground source heat pump systems
}

Tianzhen Hong, Lawrence Berkeley National Laboratory

Xaiobing Liu, Climatemaster

November 2009 


\section{DISCLAIMER}

This document was prepared as an account of work sponsored by the United States Government. While this document is believed to contain correct information, neither the United States Government nor any agency thereof, nor The Regents of the University of California, nor any of their employees, makes any warranty, express or implied, or assumes any legal responsibility for the accuracy, completeness, or usefulness of any information, apparatus, product, or process disclosed, or represents that its use would not infringe privately owned rights. Reference herein to any specific commercial product, process, or service by its trade name, trademark, manufacturer, or otherwise, does not necessarily constitute or imply its endorsement, recommendation, or favoring by the United States Government or any agency thereof, or The Regents of the University of California. The views and opinions of authors expressed herein do not necessarily state or reflect those of the United States Government or any agency thereof or The Regents of the University of California. 


\title{
Comparison of energy efficiency between variable refrigerant flow systems and ground source heat pump systems
}

\begin{abstract}
With the current movement toward net zero energy buildings, many technologies are promoted with emphasis on their superior energy efficiency. The variable refrigerant flow (VRF) and ground source heat pump (GSHP) systems are probably the most competitive technologies among these. However, there are few studies reporting the energy efficiency of VRF systems compared with GSHP systems. In this article, a preliminary comparison of energy efficiency between the air-source VRF and GSHP systems is presented. The computer simulation results show that GSHP system is more energy efficient than the air-source VRF system for conditioning a small office building in two selected US climates. In general, GSHP system is more energy efficient than the air-source VRV system, especially when the building has significant heating loads. For buildings with less heating loads, the GSHP system could still perform better than the airsource VRF system in terms of energy efficiency, but the resulting energy savings may be marginal.
\end{abstract}

Keywords: Building Simulation; DOE-2; Energy Efficiency; GSHP; VRF

\section{Introduction}

Decades after the first energy crisis in 1970s, building energy efficiency once again becomes a hot topic worldwide. Suffered from the soaring energy price in the past, people have been exploring ways to use energy more efficiently in their homes and workplaces. Improving building energy efficiency was emphasized in the new US Obama administration's plan for stimulating the economy and building a more sustainable society.

The movement towards net zero energy buildings brings tremendous challenges and opportunities to the Heating, Ventilation, Air-Conditioning, and Refrigeration (HVAC\&R) industry. Many new, or relatively new, HVAC\&R technologies are promoted with emphasis on their superior energy efficiency. Among these, the variable refrigerant flow and ground source heat pump systems are probably the most competitive technologies. They have similar advantages, including flexibility for installation, capability for individual climate control, and significant potential for energy savings. However, while GSHP systems have been used in the US for decades, VRF systems were just introduced into the US in recent years despite their popularity in Europe and Asia, and they are relatively new to many practitioners in the HVAC\&R industry [1-3].

The VRF system is an outgrowth of the "multi-split" systems used in residential applications. The big difference between VRF systems and conventional HVAC systems is that they adjust cooling/heating output by modulating the refrigerant flow continuously with the variable speed compressor. VRF systems enable a single outdoor unit to be 
connected to multiple indoor units of varying capacity and configuration throughout a building. It typically comprises of one or more centralized outdoor unit(s), which contains one or multiple compressors, one of which is an inverter-driven variable speed compressor. The indoor units contain electronic expansion valve, direct expansion coil, and fan. The outdoor and indoor units are connected with relatively long refrigerant line and controlled by dedicated controllers. There are two types of VRF systems available: one is usually referred as "heat pump" (HP) type VRF, which provides either all heating or all cooling to multiple zones at a time. As a result, in shoulder season when the core zone needs cooling while the perimeter zones need heating, supplemental heating for perimeter zones may be needed to maintain the space temperature for thermal comfort. The other is referred as "heat recovery" (HR) type VRF, which provides heating and cooling simultaneously to multiple zones with various cooling or heating demand. The VRF system is further categorized into air-source VRF and water-source VRF depending on what heat sink/source is used for the outdoor unit.

VRF system incorporates several energy efficiency technologies, including variable speed compressor and fan, heat pumping from ambient air to conditioned spaces, and heat recovery between warm and cold refrigerants, but it has some unique characteristics that may result in additional energy consumptions. First, same as other types of air source heat pumps, VRF systems need defrost the air-refrigerant heat exchanger in the outdoor unit when they run in heating mode. Second, the long refrigerant line may result in significant heat/cool loss and increased compressor power consumption. Third, some VRF systems require special "oil return" operation to get the lubricant oil back to the compressor, which consumes extra energy compared with conventional packaged air source heat pumps.

Typical GSHP system usually comprises of multiple water-to-air heat pump units, which are connected with the ground loop heat exchanger through a common two-pipe water loop. Since each of the water-to-air heat pump units can run in either cooling or heating mode independently, the GSHP system can provide simultaneous cooling and heating for different zones of the building.

VRF systems are more efficient than conventional packaged direct-expansion variable air volume (VAV) systems and central built-up VAV systems with chillers and boilers. A simulation comparison of air-source VRF systems with chilled water based systems for a moderate Brazilian climate showed VRF systems saved about 30\% energy in summer and $60 \%$ in winter [1]. Another simulation study on a prototypical ten-story office building in Shanghai China showed air-source VRF systems saved $22.2 \%$ and $11.7 \%$ energy compared with central VAV systems and fan coil systems, respectively [4]. For an existing office building in Maryland USA, VRF systems showed energy savings from 27.1 to $57.9 \%$ compared with central VAV systems depending on system configurations and design conditions [5]. Water-source VRF systems saved about 20\% energy compared with fan coil systems for a three-story office building in shanghai China [6].

Currently, there is few, if any, published literature reporting how the energy efficiency of VRF systems compares with GSHP systems. In the US, the Air-Conditioning, Heating, 
and Refrigeration Institute (AHRI) is in the process of developing rating standard AHRI 1230 for VRF systems at present time. Furthermore, energy performance of VRF systems cannot be modeled with non-proprietary building energy simulation programs like EnergyPlus [7] or DOE-2 [8], which are widely used by researcher/engineer/designer to evaluate energy performance of various types of HVAC systems. However, there are a few proprietary tools available for simulating VRF systems, such as EnergyPro and Trace 700. In addition, a customized version of EnergyPlus was developed and used for a few simulation studies on VRF systems [4-6,9]. This special version of EnergyPlus is not available to the public, and the VRF module developed for EnergyPlus was not verified or adopted by the EnergyPlus development team led by USDOE.

The most accurate and reliable way to compare the energy efficiency of VRF and GSHP systems may be to monitor two identical buildings at the same location but using VRF and GSHP systems, respectively. However, these kind of monitored data are not currently available yet to the best knowledge of the authors. Computer simulation with credible software programs is a proven feasible way to get quantitative comparison of the energy efficiency between the two types of systems. In this article, a recent effort of such simulation-based investigation is reported.

\section{Simulation approach}

The comparative result of energy efficiency between VRF and GSHP systems depends not only on the difference of the two technologies, but also on many other factors, of which the building thermal characteristics and the climate are the most dominant. In this investigation, a small office building with a conditioned floor area of $360 \mathrm{~m}^{2}$ was selected. As shown in Figure 1, this square-shape one story office building has four perimeter zones (with $4 \mathrm{~m}$ depth and one at each orientation) and one core zone. Table 1 summarizes characteristics of the building.

Table 1 Characteristics of the Small Office Building

\begin{tabular}{|l|l|l|}
\hline Component & Description & Performance \\
\hline Exterior wall construction & Metal framing with R-13 & U-factor $=0.58 \mathrm{~W} / \mathrm{m}^{2} \cdot{ }^{\circ} \mathrm{C}$ \\
\hline Roof construction & $\begin{array}{l}\text { Built-up roofing with } \\
\text { insulation }\end{array}$ & U-factor $=0.31 \mathrm{~W} / \mathrm{m}^{2} \cdot{ }^{\circ} \mathrm{C}$ \\
\hline Floor construction & $\begin{array}{l}\text { Slab-on-grade with R-30 } \\
\text { insulation }\end{array}$ & U-factor $=0.14 \mathrm{~W} / \mathrm{m}^{2} \cdot{ }^{\circ} \mathrm{C}$ \\
\hline Windows & $\begin{array}{l}\text { Double pane with low-e, } \\
\text { 30\% window-wall-ratio }\end{array}$ & $\begin{array}{l}\text { U-factor }=2.77 \mathrm{~W} / \mathrm{m}^{2} \cdot{ }^{\circ} \mathrm{C} \\
\text { SHGC }=0.43\end{array}$ \\
\hline Lighting power density & Electrical lighting & $15.0 \mathrm{~W} / \mathrm{m}^{2}$ \\
\hline Equipment power density & Plug loads & $8.0 \mathrm{~W} / \mathrm{m}^{2}$ \\
\hline Occupant density & & $18.6 \mathrm{~m}{ }^{2} / \mathrm{person}$ \\
\hline Outside air & Ventilation rate & $0.007 \mathrm{~m}^{3} / \mathrm{s} /$ person \\
\hline Cooling setpoint & Cooling thermostat & $24^{\circ} \mathrm{C}$ \\
\hline Heating setpoint & Heating thermostat & $21^{\circ} \mathrm{C}$ \\
\hline Operating schedule & $\begin{array}{l}\text { On } 6 \text { am to } 10 \mathrm{pm} \\
\text { weekdays and } 6 \text { am to } 6 \mathrm{pm}\end{array}$ & \\
\hline
\end{tabular}




\begin{tabular}{|l|l|l|}
\hline & $\begin{array}{l}\text { Saturday, off Sundays and } \\
\text { holidays }\end{array}$ & \\
\hline Air economizer & No air economizer & \\
\hline
\end{tabular}

The four perimeter zones occupy $64 \%$ of the total building floor area. The building thus has potential needs for simultaneous heating and cooling to meet the demand of all five zones year round. Two cities were selected to represent the hot and cold climates of the US: Miami and Chicago.

The building was chosen to represent typical existing buildings in terms of energy efficiency levels; it is not intended to be as energy efficient as required by current energy standard such as ASHRAE 90.1-2007.

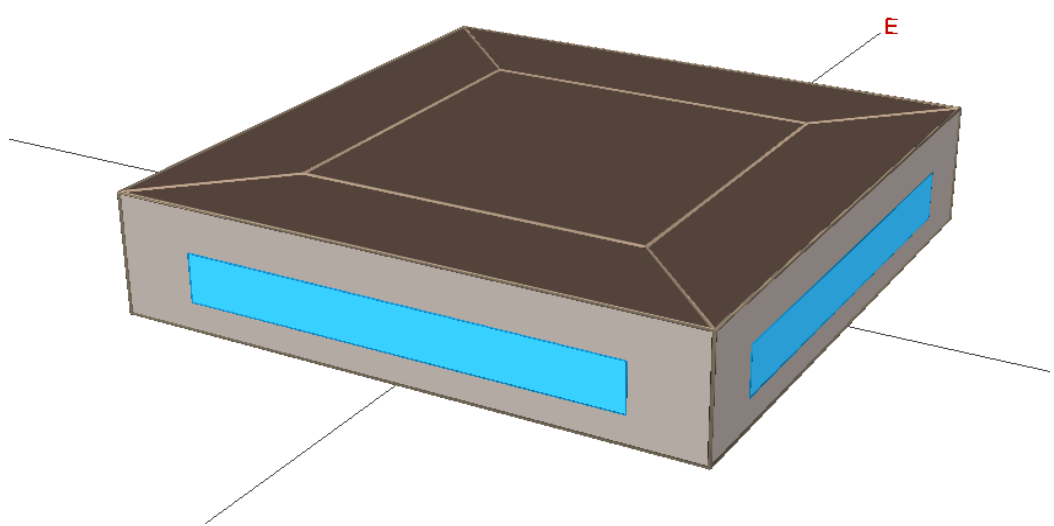

Figure 1 - 3D image of the simulated small office building

Since both HR type VRF and GSHP system can provide simultaneous heating and cooling for various spaces within a building, the energy consumption of these two systems are comparable.

For each of the two locations, a HR type air-source VRF system and a GSHP system that uses single-stage scroll compressors and vertical ground loop heat exchanger (VGLHE) are designed for the same building. For the VRF system, $7.6 \mathrm{~m}(25 \mathrm{ft})$ of equivalent refrigerant line is used, which corresponds to the standard length used in VRF manufacturers' catalog. Both the VRF and GSHP systems use R410A refrigerant. Electric heating was assumed in the VRF system for supplemental heating when the outdoor unit cannot meet the heating loads. The nominal cooling and heating capacities as well as the associated coefficient of performance (COP), and the outdoor conditions at which the two systems are operated, are summarized in Table 2. The outdoor conditions affecting the VRF and GSHP system are the ambient air dry-bulb and wet-bulb temperatures and the entering fluid temperature (EFT) of the GSHP units (the heat pump itself), respectively. 
Table 2 Nominal Capacity and Efficiency of the Simulated VRF and GSHP Systems

\begin{tabular}{|c|c|c|c|c|c|c|c|c|c|c|}
\hline \multirow[b]{2}{*}{ Location } & \multicolumn{5}{|c|}{ VRF } & \multicolumn{5}{|c|}{ GSHP } \\
\hline & $\begin{array}{c}\text { Cooling } \\
\text { Capacity }^{1} \\
{[\mathrm{~kW}]}\end{array}$ & $\begin{array}{c}\text { Heating } \\
\text { Capacity }^{1} \\
{[\mathrm{~kW}]}\end{array}$ & $\begin{array}{c}\text { Cooling } \\
\mathrm{COP}^{1}\end{array}$ & $\begin{array}{c}\text { Heating } \\
\mathrm{COP}^{1}\end{array}$ & $\begin{array}{c}\text { Outdoor } \\
\text { air temp. } \\
\text { range }{ }^{2} \\
{\left[{ }^{\circ} \mathrm{C}\right]}\end{array}$ & $\begin{array}{c}\text { Cooling } \\
\text { Capacity }^{3} \\
{[\mathrm{~kW}]}\end{array}$ & $\begin{array}{c}\text { Heating } \\
\text { Capacity }^{3} \\
{[\mathrm{~kW}]}\end{array}$ & $\begin{array}{c}\text { Cooling } \\
\mathrm{COP}^{3}\end{array}$ & $\begin{array}{c}\text { Heating } \\
\mathrm{COP}^{3}\end{array}$ & $\begin{array}{c}\text { Entering } \\
\text { fluid temp. } \\
\text { range }^{4}\left[{ }^{\circ} \mathrm{C}\right]\end{array}$ \\
\hline Miami & 31.6 & 35.2 & 3.3 & 3.5 & $3.3-33.9$ & 38.2 & 24.9 & 5.9 & 4.2 & $24.7-32.8$ \\
\hline Chicago & 36.9 & 41.0 & 3.3 & 3.5 & $\begin{array}{c}-22.8- \\
35.5\end{array}$ & 54.7 & 35.8 & 5.9 & 4.2 & $2-25$ \\
\hline
\end{tabular}

Note:

1. For the VRF system, according to manufacturer performance data, cooling capacity and COP are measured when the outdoor dry bulb temperature is $35^{\circ} \mathrm{C}$ and the heating capacity and COP are measured when the outdoor wet bulb temperature is $6^{\circ} \mathrm{C}$.

2. Outdoor air temperature range is obtained from TMY2 weather data used in the simulation.

3. For GSHP units, per industry standard (ARI/ASHRAE/ISO 13256-1), the cooling capacity and COP are measured at $25^{\circ} \mathrm{C} \mathrm{EFT}$; the heating capacity and COP are measured at $0^{\circ} \mathrm{C} \mathrm{EFT}$.

4. Entering fluid temperature is from GSHP system simulation results of each location.

Outdoor ventilation air is assumed going directly from outdoor to individual zone. The fan of each GSHP unit and the indoor unit of the VRF system is assumed running continuously to provide air circulation when the building is occupied. Variable speed pump is assumed being used in the GSHP system.

In order to evaluate how the length of the refrigerant line of the air-source VRF system affects its energy performance, an additional scenario is investigated for the building in Chicago. In this case, the refrigerant line is $174 \mathrm{~m}$ (574 ft), which is about the longest length allowed for this particular VRF system.

\section{Simulation tools}

Among the available simulation tools for VRF systems, EnergyPro is perhaps the only one accepted by major VRF manufacturers. EnergyPro is a comprehensive energy analysis program that uses DOE-2.1E as the simulation engine. Since DOE-2 cannot directly model VRF systems, a DOE-2 user function was developed to calculate the cooling, heating, and fan energy use of a VRF system based on the zone loads calculated by DOE-2. The user function uses performance data/curves of VRF systems provided by major manufacturers.

The VRF user function for DOE-2.1E was validated by comparing the hourly results from the VRF function with the hand coded spreadsheet hourly calculations using output reports (zone loads and zone and outside air temperatures) from DOE-2.1E and the same VRF performance curves and algorithm used in the VRF function. It would be important to compare simulated VRF energy performance with measured VRF energy consumption when these data become available in the future.

The electricity consumption of a HR type VRF system includes indoor fan power, refrigerant management system (branch controller) power, and outdoor unit power. The operation mode of the outdoor unit is determined by comparing the total cooling loads of 
zones in cooling mode and the total heating loads of zones in heating mode at each hour. If the total cooling load is higher than the total heating load, the outdoor unit operates in cooling mode, otherwise in heating mode. The actual load on the outdoor unit is the maximum of the total cooling loads and the total heating loads. This algorithm does not account for any possible loss of heating/cooling capacity of the HR type VRF system due to the complicated refrigerant management system. Detailed calculation algorithm is described in VRF manufacturers' application to California Energy Commission for code compliance credits for VRF systems [10].

Simulation of the GSHP system was conducted with eQUEST [11], a building energy analysis program powered by DOE-2.2. In the current version of eQUEST/DOE-2.2, a model based upon the widely accepted g-function algorithm [12] has been implemented to simulate the performance of the VGLHE, one of the most critical components of GSHP systems [13]. In addition, a user interface and associated database for specifying VGLHE related parameters have also been created and integrated into the Building Creation Wizard of eQUEST. The performance data/curves of GSHP units used in the eQUEST simulation are from a major GSHP equipment manufacturer.

The GSHP system simulation of eQUEST was validated in three ways: the eQUEST predicted GLHE leaving fluid temperatures were compared with those from HVACSIM+ simulation which had been experimentally validated [13]; the eQUEST predicted GLHE leaving fluid temperatures were compared with measured data [14]; and the eQUEST predicted GSHP system energy consumption was compared with measured data, which will be published in a separate article. These validation results showed that eQUEST can fairly well predict the leaving fluid temperature of VGLHE, which is the entering fluid temperature of the ground source heat pump, and the energy consumption of the whole GSHP system given the accurate information of the building, GSHP system, weather data, and other related parameters being input properly into eQUEST.

\section{Performance curves}

The performance (i.e. heating/cooling capacity and efficiency) of VRF and GSHP equipments at various operating conditions can be associated with the performance at certain "reference conditions" with a set of correction factors. In the following, a set of generic performance curves of the simulated VRF system and GSHP units are presented. These generic performance curves are curve-fits of tabulated manufacturer performance data of the VRF and GSHP equipments.

Figure 2(a) and 2(b) show the performance curves of heating/cooling capacity and efficiency of the simulated VRF system in response to various outdoor air temperatures, respectively. The performance curves of cooling capacity and efficiency are normalized at $35^{\circ} \mathrm{C}$ outdoor dry bulb temperature (ODBT). The performance curves of heating capacity and efficiency are normalized at $6^{\circ} \mathrm{C}$ outdoor wet bulb temperature (OWBT).

Two performance curves are used for the heating capacity. The first curve accounts for the impact of OWBT and the second curve represents the effect of defrosting 
operation. As shown in these curves, heating capacity of the VRF system decreases almost linearly down to $50 \%$ of its nominal heating capacity when OWBT goes down to $-20^{\circ} \mathrm{C}$, the minimum allowed temperature. Defrosting operation further degrades the heating capacity when OWBT is below $5^{\circ} \mathrm{C}$. On the other hand, the cooling capacity of the VRF system seems not very sensitive to ODBT. For a $\pm 10^{\circ} \mathrm{C}$ variation from the reference temperature $\left(35^{\circ} \mathrm{C}\right)$, the change of cooling capacity is about $10 \%$ of its nominal value.

The energy efficiency is represented with the ratio of electric input to heating/cooling capacity and abbreviated as "EIR" in the figure. As shown in the figure, the heating EIR of the VRF system has a peak around $3^{\circ} \mathrm{C}$ OWBT when defrosting operation most adversely affected the heating capacity as shown in Figure 2(a). Clearly, the defrosting operation will significantly degrade the heating performance of the VRF system. Same as for the cooling capacity, the performance curve shows almost linear relationship between cooling EIR and ODBT. For the same $\pm 10^{\circ} \mathrm{C}$ variation from the reference temperature $\left(35^{\circ} \mathrm{C}\right)$, the change of cooling EIR is about $20 \%$ of its nominal value.

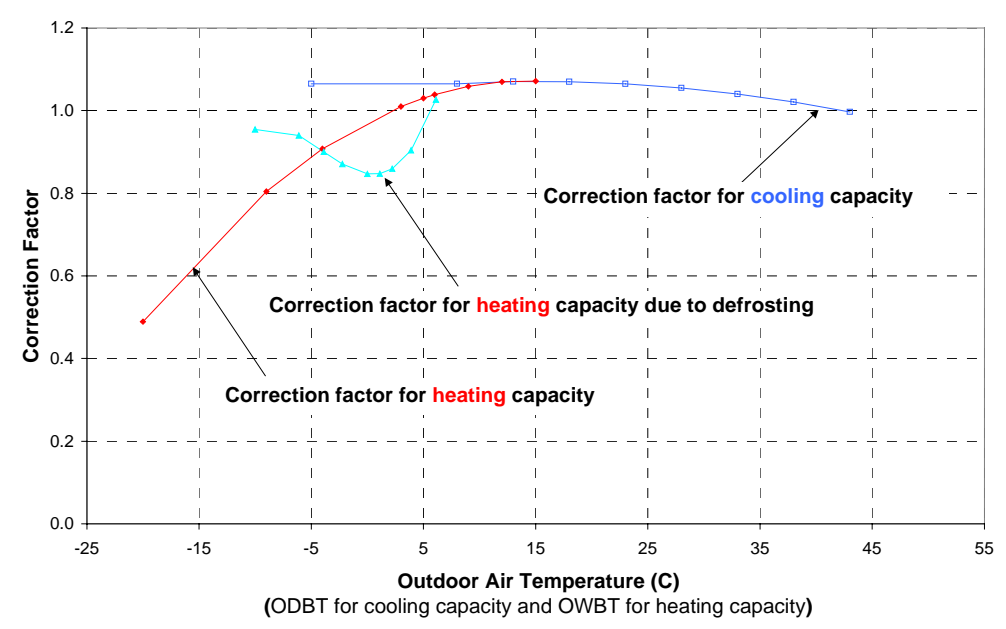

Figure 2(a) - Performance curves of heating and cooling capacity of the simulated VRF system in response to various outdoor air temperatures 


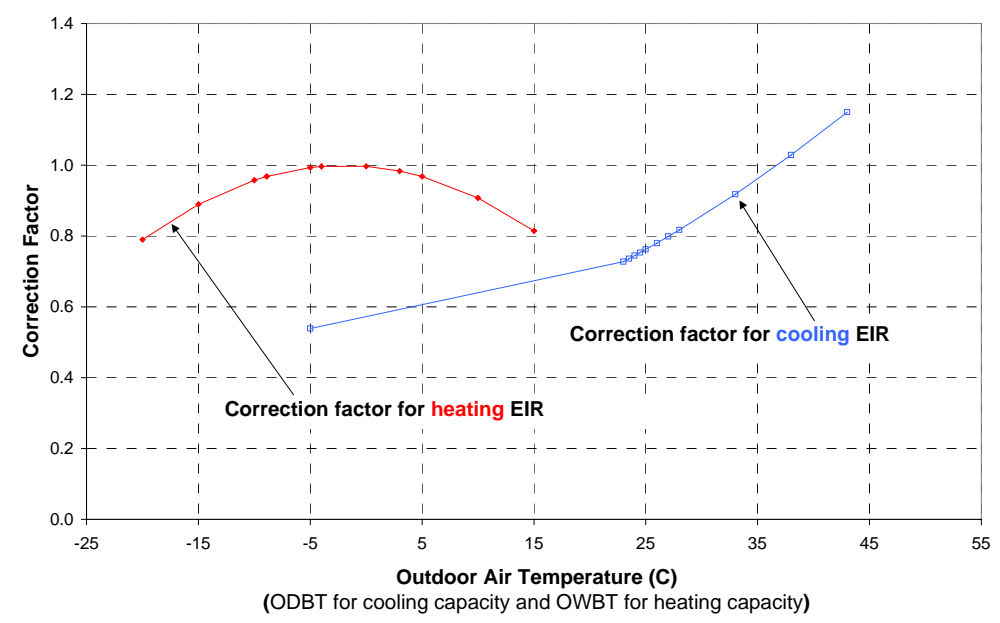

Figure 2(b) - Performance curves of heating and cooling efficiency of the simulated VRF system in response to various outdoor air temperatures

Figure 3(a) and 3(b) show the performance curves of heating/cooling capacity and EIR of the simulated GSHP units in response to various entering fluid temperatures, respectively. Per the industry standard previously stated, the performance curves of cooling capacity and EIR are normalized at $25^{\circ} \mathrm{C}$ EFT and the performance curves of heating capacity and EIR are normalized at $0^{\circ} \mathrm{C}$ EFT. As shown in the figures, an increase in EFT results in higher capacity and lower electric consumption for heating, but results in lower capacity and higher electric consumption for cooling. This implies that the actual performance of a GSHP system strongly depends on the building loads (cooling dominated vs. heating dominated) and the EFT, which is affected by geological conditions (i.e. ground temperature and thermal conductivity) where the GSHP system is installed.

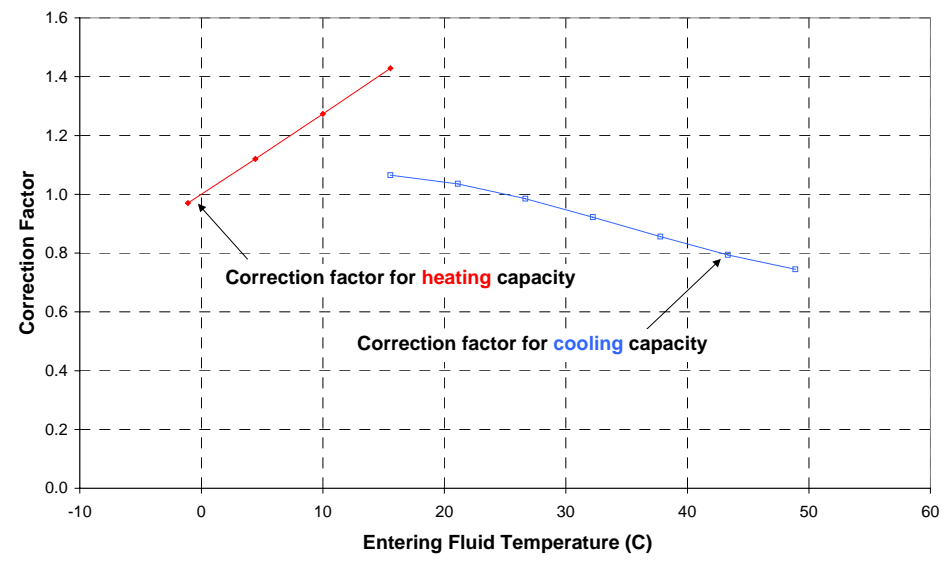

Figure 3(a) - Performance curves of heating and cooling capacity of the simulated GSHP units in response to various entering fluid temperatures 


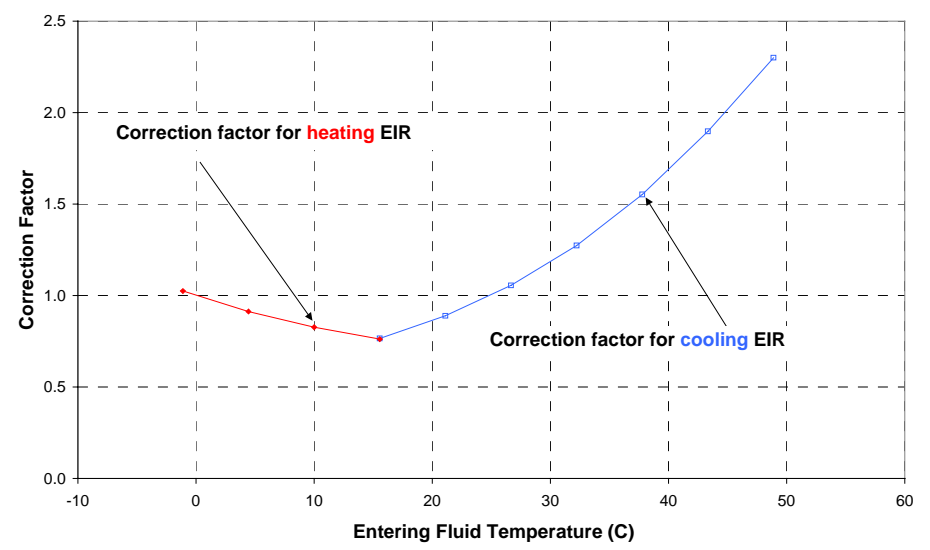

Figure 3(b) - Performance curves of heating and cooling efficiency of the simulated GSHP units in response to various entering fluid temperatures

In addition to the outdoor conditions, the energy efficiency of VRF and GSHP systems is also affected by the capability of adjusting heating/cooling output to meet the varying building heating/cooling load. This capability is usually characterized by the performance curve of "Part Load Factor" (PLF) in response to various "Part Load Ratio" (PLR), which is the ratio of building heating/cooling load to the available heating/cooling capacity of a HVAC system. For a system with better energy efficiency at part load condition (when the load is smaller than the available capacity), the PLF at given PLR will be less than PLR, which means the system uses less energy than an "ideal” system that adjusts its output by turning on and off but without any cycling loss.

Figure 4(a) and 4(b) show the part load performance curves of the simulated VRF system and GSHP units. Data on the diagonal lines in each figure indicate that the PLF exactly matches the given PLR. As shown in Figure 4(a), the PLF of the simulated VRF system is below the diagonal line when it runs in cooling mode and PLR is bigger than 0.4 , but it is slightly above the diagonal line when the VRF system runs in heating mode. It means that the VRF system has better energy efficiency than the "ideal" system in cooling mode, but not in heating mode, which is probably due to the defrosting operation. Contrastingly, as shown in Figure 4(b), the simulated GSHP units have part load performance very close to that of the "ideal" system. 


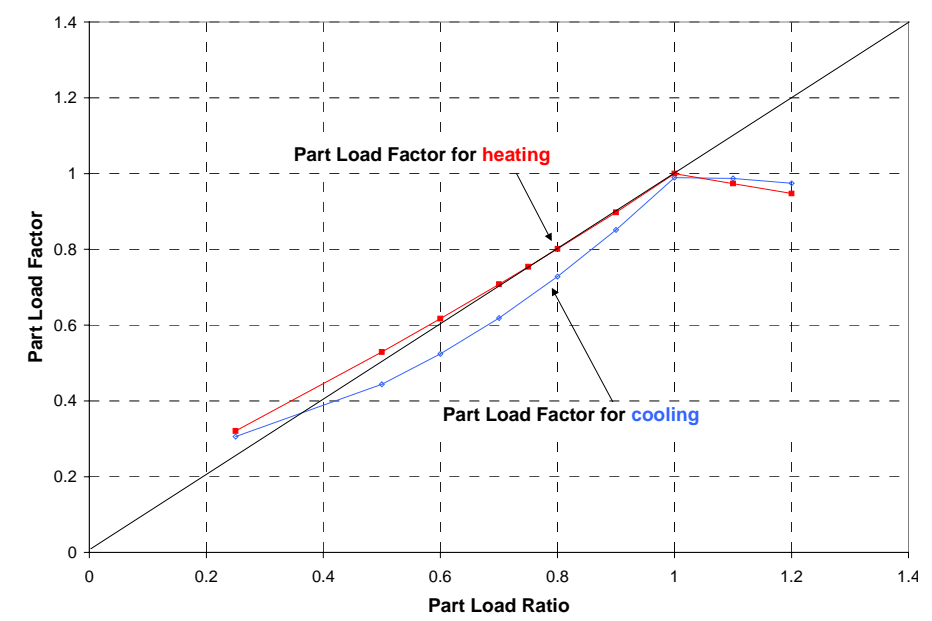

Figure 4(a) - Part load performance curves of the simulated VRF system

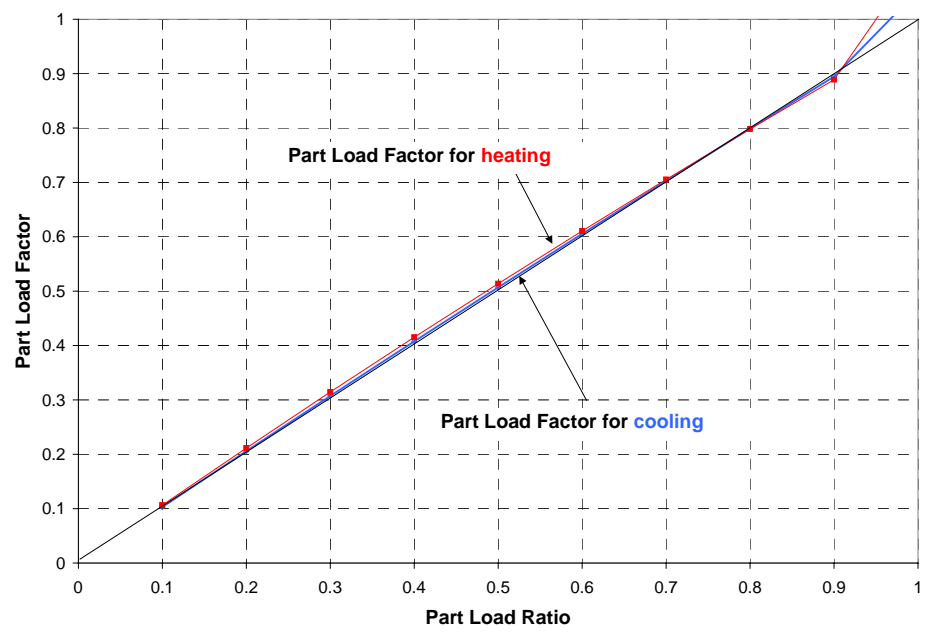

Figure 4(b) - Part load performance curves of the simulated GSHP units

Compared with typical packaged GSHP units, VRF system usually has much longer refrigeration line connecting a few outdoor units with dozens of indoor units throughout the building. The longer refrigeration line not only requires larger amount of refrigerant in the system, but also results in loss of heating/cooling capacity as well as increased compressor power consumption. EnergyPro uses a set of manufacturer provided correction factors to account for the impact of refrigeration line length on the heating/cooling capacity of the VRF system. However, there is no correction to account for the increased compressor power consumption resulting from longer refrigeration line in the VRF system. 


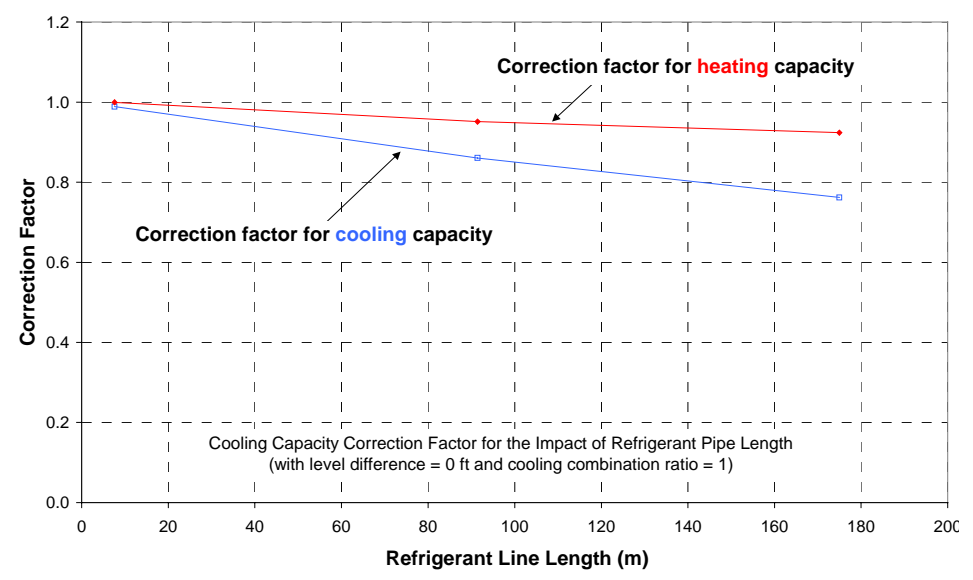

Figure 5 - Impact of refrigeration line length on heating and cooling capacity of the simulated VRF system

As shown in Figure 5, the length of the refrigeration line significantly affects both the heating and cooling capacity of the simulated VRF system. It appears that the cooling capacity is more sensitive to the refrigeration line length than the heating capacity. It may indicate that, in cooling mode, some refrigerant has been evaporated while being transported through the refrigerant line before entering the indoor units.

Although there is no long refrigeration line in the GSHP system, it does have a twopipe water loop that connects the VGLHE with multiple GSHP units installed in the building. It thus consumes additional pumping energy to move water through the circulation loop, VGLHE, and all the GSHP units.

\section{Simulation results}

Simulations of the VRF and GSHP systems were conducted with EnergyPro and eQUEST, respectively. Since both the VRF and GSHP systems circulate same amount of air in each zone and assume the required total static pressure of the fans in the GSHP units and the VRF indoor units are the same, the total electricity consumed by the fans of the two systems is equal.

Table 2 summarizes results of annual total electricity consumption by HVAC end use of the simulated VRF and GSHP systems at three different locations. As can be seen in the table, the GSHP system saves $9.4 \%$ and $24.1 \%$ electricity compared with the VRF system for the same office building located in Miami and Chicago, respectively. The results show clearly that the electricity savings goes up with the increasing heating demands. While the GSHP system is more energy efficient than the VRF system in both locations, it performs much better in places like Chicago where substantial heating and cooling are needed. 
Table 2 Annual HVAC Electricity End Uses

\begin{tabular}{|l|l|r|r|}
\hline System / Location & Miami & Chicago \\
\hline VRF \\
Annual electricity Use $[\mathrm{kWh}]$ & Cooling & 17,358 & 6,271 \\
\cline { 2 - 4 } & Heating & 121 & 9,116 \\
\cline { 2 - 4 } & Fan & 4,740 & 5,080 \\
\cline { 2 - 4 } & Total HVAC & 22,219 & 20,467 \\
\hline \multirow{3}{*}{ GSHP } & Cooling & 13,388 & 3,829 \\
\cline { 2 - 4 } & Heating & 82 & 4,454 \\
\cline { 2 - 4 } & Fan & 4,740 & 5,080 \\
\cline { 2 - 4 } & Pump & 1,924 & 2,177 \\
\cline { 2 - 4 } & Total HVAC & 20,134 & 15,540 \\
\hline Total HVAC Electricity Savings kWh & & 2,085 & 4,927 \\
\hline Total HVAC Electricity Savings \% & & $9.4 \%$ & $24.1 \%$ \\
\hline
\end{tabular}

Figure 6 shows comparison results between the GSHP system and two variations of the VRF system. As shown in this figure, increasing the length of refrigerant line could result in higher electricity consumption of the VRF system, especially for cooling. The electricity savings of the GSHP system goes up to 33\% compared with the HR type VRF system using $174 \mathrm{~m}$ long refrigerant line.

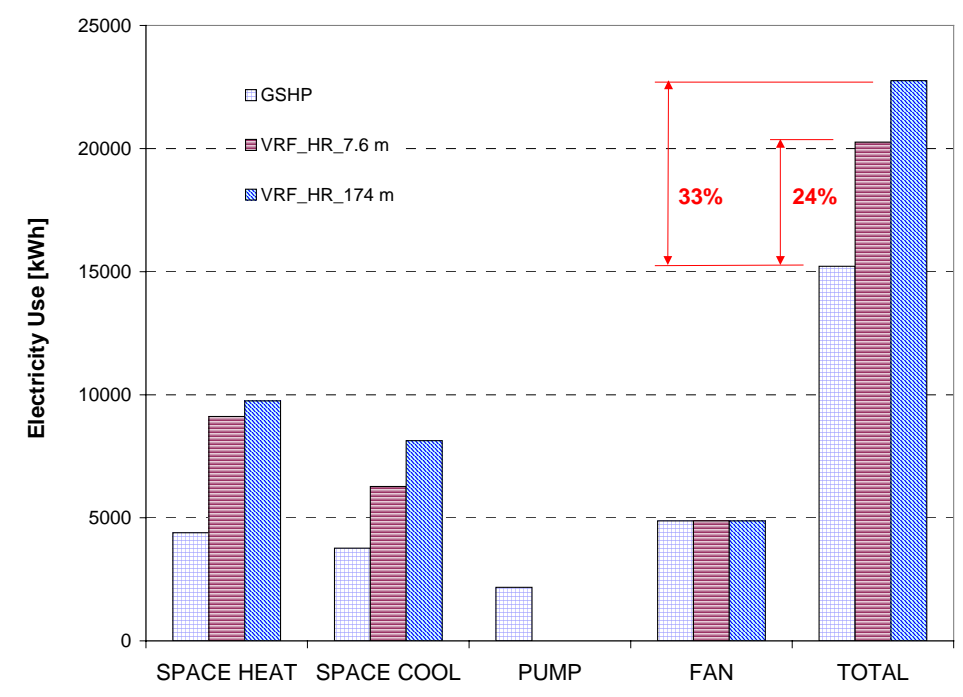

Figure 6 - Annual electricity consumption of the VRF and GSHP systems in Chicago

\section{Conclusions and discussion}

A preliminary comparison of energy efficiency between the air-source VRF and GSHP systems was conducted using available building energy analysis software and the performance data/curves from VRF and GSHP equipment manufacturers. The results show that, for conditioning the same small office building, GSHP system is more energy efficient than VRF system. For the two locations representing hot and cold climates, GSHP system saves $9.4 \%$ to $24.1 \%$ of HVAC energy compared with the "heat recovery" type VRF system with the standard rated refrigerant piping length. More energy savings of GSHP system could be expected if longer refrigerant line is used in the VRF system. 
Please note that with different building load profiles, climates, and HVAC system configurations, the relative energy performance of the VRF and GSHP systems will vary. The water-source VRF systems also have different energy performance from the airsource VRF systems. Also in this study, each GSHP unit has a single stage compressor, which is less efficient than the GSHP unit with dual compressor available on the market [15].

Compared with the selected building, a more energy efficient building will have lower space cooling and heating loads, which allows a smaller VRF or GSHP system to serve the building. In this case, the total cooling and heating energy consumption of the building would be lower, but the relative energy performance between the air-source VRF and GSHP systems for the more energy efficient building in the same climate would be similar. For other climates such as the mild climate of San Francisco, the GSHP energy savings over the air-source VRF are not as significant as in Chicago due to the low cooling loads and modest heating loads in San Francisco for the same building. In general, GSHP system is more energy efficient than the air-source VRV system (which is basically an air source heat pump), especially when the building has significant heating loads. It is simply due to that the "free" energy stored in the ground is much more than that in cold air. For buildings with less heating loads , the GSHP system could still perform better than the air-source VRF system in terms of energy efficiency, but the resulting energy savings may be marginal.

This study did not compare the installation cost, reliability, and other non-energy aspects of the VRF and GSHP systems, which can be key factors to consider by design engineers and building owners in determining which technology to deploy.

\section{References}

[1] W. Goetzler, K.W. Roth, J. Brodrick, Variable flow and volume refrigerant system, ASHRAE Journal, January 2004, 24-31.

[2] W. Goetzler, Variable refrigerant flow systems, ASHRAE Journal, April 2007, 24-31.

[3] A. Amarnath, M. Blatt, Variable refrigerant flow: where, why, and how, Engineered Systems, February 2008, 54-60.

[4] Y.P. Zhou, J.Y. Wu, R.Z. Wang, S. Shiochi, Energy simulation in the variable refrigerant flow air-conditioning system under cooling conditions, Energy and Buildings 39 (2007) 212-220.

[5] T.N. Aynur, Y. Hwang, R. Radermacher, Simulation comparison of VAV and VRF air conditioning systems in an existing building for the cooling season, Energy and Buildings (2009) In Press. 
[6] Y. Li, J.Y. Wu, S. Shiochi, Modeling and energy simulation of the variable refrigerant flow air conditioning system with water-cooled condenser under cooling conditions, Energy and Buildings 41 (2009) 949-957.

[7] USDOE, EnergyPlus, www.energyplus.gov.

[8] Lawrence Berkeley National Laboratory, DOE-2, gundog.lbl.gov/dirsoft/d2whatis.html.

[9] Y.P. Zhou, J.Y. Wu, R.Z. Wang, S. Shiochi, Y.M. Li, Simulation and experimental validation of the variable-refrigerant-volume (VRV) air-conditioning system in EnergyPlus, Energy and Buildings 40 (2008) 1041-1047.

[10] Energysoft, Application for adoption of variable refrigerant flow systems under the Title 24-2005 nonresidential ACM procedures, submitted to California Energy Commission, 2008.

[11] Jeff Hirsch Associates, eQuest, http://doe2.com/equest/index.html.

[12] P. Eskilson, Thermal analysis of heat extraction boreholes, Doctoral Thesis, Lund University, Sweden, 1987.

[13] X. Liu, G. Hellstrom, Enhancements of an integrated simulation tool for groundsource heat pump system design and energy analysis, 10th International Conference on Thermal Energy Storage, Richard Stockton College of New Jersey, 2006.

[14] X. Liu, Enhanced design and energy analysis tool for geothermal water loop heat pump systems, 9th International IEA Heat Pump Conference, Zürich, Switzerland, 2008.

[15] X. Liu, Performance of ground source heat pump system in a near-zero energy home, IEA Heat Pump Center Newsletter 26 (2) (2008) 32-35.

This work was supported by the U.S. Department of Energy under Contract No. DE-AC02-05CH11231. 